\title{
PATIENT-RELATED BARRIERS TO PAIN MANAGEMENT- THE IRANIAN BARRIERS QUESTIONNAIRE II (IR-BQII)
}

\author{
Samira Jafari', Roya Sadeghi², Mitra Ebrahimpoor³, Mohammad Hossein Baghiani Moghadam ${ }^{4}$, Mehri Alaviani ${ }^{5}$
}

1Ph.D in Health Education \& Promotion, Assistant Professor, Department of Public Health, Maragheh University of Medical Sciences, Maragheh, Iran.

2Ph.D in Health Education \& Promotion, Associated Professor. Department of Health Education \& Promotion, School of Public Health, Tehran University of Medical Sciences, Tehran, Iran.

${ }^{3}$ Ph.D student in Medical Statistics, Department of Epidemiology and Biostatistics, Tehran University of Medical Sciences, Tehran, Iran. ${ }^{4}$ Ph.D in Health Education \& Promotion, Professor, Shahid Sadoughi University of Medical Sciences, Yazd, Iran.

${ }_{5}^{5}$ Sc in Nursing, Lecturer, Patient Safety Research Center, Urmia University of Medical Sciences, Urmia, Iran.

\section{BACKGROUND}

ABSTRACT

Successful pain management depends on acknowledgment of barriers that interfere with providing adequate pain relief. However, there are no consensus tools in Persian to identify these barriers. This article presents the psychometric properties of a Persian questionnaire for assessing perceived barriers to manage cancer pain. In this study, we aimed to determine the barriers to achieving optimal pain management, and assess validity and reliability of IR-BQII scale among Iranian patients. Assessment of the barriers in our society using this questionnaire guides effective plans of pain management to bring about more relief and welfare for cancer patients.

\section{MATERIALS AND METHODS}

170 cancer patients participated in this cross-sectional study. Subjects were either new outpatients or previous outpatients (now hospitalized) who were referred to the oncology clinic of Imam Khomeini Hospital (Cancer Research Center, Tehran University of Medical Sciences) in Tehran, Iran. BQII validity was determined by exploratory factor analysis (FA). Reliability and consistency were assessed using Cronbach's alpha coefficient.

\section{RESULTS}

Four factors sufficiently explained the variability in the data: Communication and Psychological Side Effects, Addiction and Fatalism, Physiological Side Effects, and Beliefs about Consciousness Status. Internal reliability was 0.708 based on Cronbach's alpha coefficient. The internal consistency of the different subscales was within 0.69-0.80. Pain management barriers' score was higher among middle-aged patients.

\section{CONCLUSION}

IR-BQII is a valid and reliable instrument for physicians, nurses and other clinical staff to identify pain management barriers and eliminate or modify them to help ease the pain for cancer patients.

\section{KEY WORDS}

Cancer Pain, Pain Management, Barriers Questionnaire, IR-BQII

HOW TO CITE THIS ARTICLE: Jafari S, Sadeghi R, Ebrahimpoor M, et al. Patient-related barriers to pain management- the Iranian barriers questionnaire II (IR-BQII). J. Evolution Med. Dent. Sci. 2019;8(12):896-901, DOI: 10.14260/jemds/2019/200

\section{BACKGROUND}

National surveys indicate that cancers are third cause of death in in Iran.(1) Cancer is a fourth leading cause of the burden of disease in the nation which imposes heavy costs on families and society.(2) Cancer studies incorporate many aspects including physical and mental health issues of cancer patients and their families. Undoubtedly, cancer causes severe pain.(3) One out of three cancer patients with active disease suffers pain; the ratio is two out of three for advanced disease. (4) Patients convey pain as distressful, horrible and excruciating.(5) Pain is a subjective experience with no objective biological indicator.

'Financial or Other Competing Interest': None.

Submission 27-10-2018, Peer Review 10-03-2019,

Acceptance 16-03-2019, Published 25-03-2019.

Corresponding Author:

Mehri Alaviani,

Urmia University of Medical Sciences,

Urmia, Iran.

E-mail: samira.jafari1985@gmail.com

DOI: $10.14260 /$ jemds $/ 2019 / 200$

\section{(c) (1) () $९$}

Therefore, patient's self-report provides the most valid measure as. $(6,7)$

Effects of cancer pain can be devastating and can result in severe consequences such as depression,(8-10) less social contacts,(11,12) sleep disorders,(5,13) movement disorders,(5,14) poor physical functioning and psychological well-being, $(5,12,15)$ impaired daily functioning(16) and increased risk of suicide.(10) Research suggests that along with secondary physical, mental and social problems, pain has an adverse effect on the quality of life of cancer patients.(15) These problems affect not only the patients but also their close friends, family and acquaintances. Patients and their families fear pain even more than death.(17-21) Furthermore, higher levels of pain are associated with incremental costs of health care.

As another implication of persistent pain, studies showed that a relative in pain can impose many psychological and social responsibilities on the other members of the family, including mood disorders, and family disruption.(22,23) Pain management skills are crucial for cancer patients, their families and care-takers. The acknowledgement of "pain is 
manageable" can improve pain-management and is positively correlated with mental well-being, $(24,25)$ quality of life,(26) patient satisfaction(27) and patient adherence.(28)

Some studies showed that a sense of control in pain management process is correlated with reduced pain experience, less use of the health-care resources and faster recovery after surgical procedure. $6,7,14)$ In general, a strong sense of control on the process of care and treatment can reduce patient's anxiety and help them to plan, prepare for and adopt to acceptable practices of pain management.(29) This is in accordance with social learning theory. In addition, perceived self-efficacy in pain control can activate opioid and non-opioid analgesia mechanism.(30) Likewise, depletion in pain control is associated with disability, pain severity, distress, depression and anxiety. (25,31-33)

Improper pain management can influence treatment process. Many studies showed that unattended cancer pain is associated with belief and attitude of patients and care-takers rather than inadequate treatment.(34-38) According to literature, barriers to effective pain management are physician ${ }^{(39,40)}$ health care system and the patient.(39-42) Although patients have a strong incentive to relief from pain, many are not willing to talk about pain and fear addiction and/or physical dependence.(43)

Despite all the improved techniques, strategies and many guidebooks, ignoring the above-mentioned barriers will severely interrupt pain management process. As an example, in a study by Cleeland, $90 \%$ of cancer patients reported pain, and $42 \%$ did not receive adequate pain relief $(42,44-46)$ while studies have shown that up to $90 \%$ of cancer patients can be pain-relieved.(43,45-47) Patient related barriers have been studied, too. It seems that reluctance to both reporting pain and using available medications are the main obstacles to effective treatment,(48) which is often due to incorrect beliefs about pain and pain medications. BQII barriers questionnaire, designed by Ward et al. in 1993 is used to evaluate these beliefs. (40) Updated later by Gunnarsdottir et al,(49) it has been used in many countries and has been approved for its reliability and validity.(21,49-52)

So far, barriers to control pain and effective agents are not well-established in Iran; and to our knowledge, this scale is not implemented in any studies. Assessment of the barriers is a requirement for effective pain management to bring about more relief and welfare for cancer patients. To this end, we aimed to determine the barriers to optimal pain management and assess the validity and reliability of IR-BQII scale among Iranian cancer patients.

\section{MATERIALS AND METHODS \\ Design and Sample}

This was a cross-sectional study of 170 cancer patients. Subjects were either new outpatients or previous outpatients (now hospitalized) who referred to the oncology clinic of Imam Khomeini Hospital (Cancer Research Center, Tehran University of Medical Sciences) in 2015.

The original scale has 27 items, each with a 6-point Likert scale answering format. A sample size of $170(27 \times 6=162)$ was chosen to have a sample per each possible answer. The inclusion criteria were as follows: cancer patients, over 18 years of age, willingness to participate in the study, ability to communicate and answer the questions, and no history of painkillers abuse or addiction. All subjects signed a written consent form. It was made clear to the patients that they can choose to quit the study at any time. The study design was in accordance with the Helsinki Declaration and was approved by the independent ethics committee of Shahid Sadoughi University of Medical Sciences and Health Services.

\section{Instruments}

Data collection was based on two questionnaires. A demographic and disease related questionnaire and barrier questionnaire. The original barrier's questionnaire is a selfreport questionnaire with 6-point Likert scale responses.

\section{Patient's beliefs are evaluated in 8 dimensions-}

1. Fear of addiction.

2. Fatalistic believes (Cancer Pain is not Predictable).

3. Concerns about drug tolerance.

4. Concerns about side effects.

5. Fear of losing ability to monitor changes in body.

6. Fear of damaging the immune system with drug.

7. Tendency to be a good patient.

8. Concerns about distracting the physician from curing the cancer.

The questionnaire is divided into 4 categories-

1. Physiologic effect (12 items)

2. Fatalism (3 items)

3. Communication (6 items)

4. Harmful effect (6 items)

Total score of the scale ranges between 0-135.

\section{Procedures}

Dr. Sandra Ward's permission was obtained to use the questionnaire. Translation was based on backward-forward method. First, two native experts with great English language skills translated the questionnaire into Persian. A team of bilingual professionals, including a nurse, a doctor, a palliative medicine specialist and a specialist in health education and promotion, reviewed and evaluated the translation. Then, two individuals fluent in both Persian and English who were blind to the original English questionnaire translated the Persian version back into English. The two versions of the scale in English were compared. Items with very similar meaning in Persian version were omitted. Therefore, the Iranian version includes only 18 items. The items were evaluated by a 3-point Likert scale to avoid ambiguity (Disagree=0, Neutral $=1$ and Agree=2). The total score range became $0-36$. In addition, three severity categories were defined based on the total score: No Barriers (Total Score $=0$ ), Moderate (Total Score $=1-18$ ), and Sever (Total Score $=19-36$ ).

Final version of the questionnaire was used in a pilot study of 20 patients. Participants, who met inclusion criteria, received initial instructions. They filled out the questionnaire, were interviewed for 20-30 minutes, and 2-3 weeks later came back for a re-test. Finally, the questionnaire was updated one last time according to the results of the pilot study. 


\section{Data Analytic Approach}

Statistical analyses were performed using SPSS version 16. A principal axis factor analysis with oblique rotation was applied to detect the latent variables, number of factors was chosen based on a scree-plot. Reliability and Consistency was evaluated based on Cronbach's alpha. Nonparametric tests were used to study the effects of demographic and disease related factors on IR-BQII score. Mann-Whitney U test was used for variables with two levels. For variables with more than two levels Kruskal-Wallis test was carried out. Parametric tests were not applicable since normality assumption was not satisfied using Kolmogorv-Smirov test.

\section{RESULTS}

\section{The Barriers Questionnaire II}

According to scree-plot, four factors would sufficiently explain the variability in data (Figure-1). The results of the analysis including factor loading and explained variances are presented in Table- 1 and Table- 2 . Internal reliability of the scale based on Cronbach's alpha was 0.708 . The internal consistency of the derived factors was assessed using Cronbach's alpha as listed in Table-3.

The first factor was labelled Communication and Psychologic Side Effect. Two items concerned physician's distraction from treatment process and annoyance to hear about the pain. Examples of high loading communication item were "Doctors might find it annoying to be told about pain", "If patient talk about pain, people will think they are complaining". Further, 6 items dealt with side effect; 2 items of this factor reflected drug avoidance due to strange and embarrassing behaviour under the influence of drugs, and that "I'd rather enduring pain than suffering from side effects" and finally items addressing tolerance, like: "taking drug for mild pain will cause ineffectiveness of painkillers in future".

The second factor was labelled Addiction and Fatalism which include items regarding fatalistic beliefs and fear of addiction to pain medications. Fatalism was loaded on three factors, but had the highest loading on this factor. A communication related item with a high loading in factor two was also loaded in three factors, and through further analysis this item is considered with other communication items in factor one. Constipation side effect was also loaded in both factor 2 and factor 3 , but it was considered alongside with other side effects in factor 3 .

The third factor was labelled Physiologic Side Effect which included items focusing on concerns about nausea and adverse effect of analgesic use on immune system. Monitoring and tolerance items were also loaded in this factor including inability to detect change in body and drug tolerance.

The fourth factor was labelled Beliefs about Consciousness Status and included items concerning side effects like dizziness and drowsiness due to painkiller use. A communication item stating that: "It is important to be strong by not talking about pain", was loaded in all 4 factors but had its highest factor loading on this factor. For theoretical reasons, and the fact that it loaded in other factors, it was considered within factor one.

\section{The BQII with Demographic Variables}

The age range of the sample was 18-84 years, but most participants (30.6\%) aged 49-58. Kruskal-Wallis test showed a significant relation between age and IR-BQII. There was no significant effect of other demographic variables on IR-BQII according to the results of either Mann-Whitney U or KruskalWallis tests. Table- 4 includes descriptive statistics along with the test results for each demographic variable. Parametric tests were not applicable since normality assumption was not satisfied based on Shapiro-Wilk test (P-value=0.019).

\begin{tabular}{|c|c|c|c|}
\hline Factor & Eigenvalue & $\begin{array}{c}\text { Explained } \\
\text { Variance }\end{array}$ & $\begin{array}{c}\text { Cumulative } \\
\text { Variance }\end{array}$ \\
\hline 1 & 10.3 & 55.72 & 55.72 \\
\hline 2 & 2.39 & 13.31 & 69.03 \\
\hline 3 & 1.45 & 8.09 & 77.12 \\
\hline 4 & 1.11 & 6.20 & 83.33 \\
\hline \multicolumn{4}{|c|}{ Table 1. Variance Explained by Each Factor with } \\
Eigenvalues \\
\hline
\end{tabular}

\begin{tabular}{|c|c|c|c|c|}
\hline Items & Factor 1 & Factor 2 & Factor 3 & Factor 4 \\
\hline Tolerance 1 & 0.262 & 0.249 & 0.842 & 0.238 \\
\hline Tolerance 2 & 0.920 & 0.243 & 0.139 & 0.190 \\
\hline Distractibility 1 & 0.243 & 0.855 & 0.224 & 0.253 \\
\hline Distractibility 2 & 0.920 & 0.243 & 0.144 & 0.194 \\
\hline Distractibility 3 & 0.859 & 0.039 & 0.235 & 0.175 \\
\hline Be Good 1 & 0.329 & 0.341 & 0.232 & 0.440 \\
\hline Be Good 2 & 0.919 & 0.235 & 0.150 & 0.201 \\
\hline Immune System & 0.194 & 0.177 & 0.839 & 0.141 \\
\hline Addiction & 0.170 & 0.839 & 0.142 & 0.205 \\
\hline Fatalism 1 & 0.479 & 0.426 & 0.357 & 0.519 \\
\hline Fatalism 2 & 0.807 & 0.184 & 0.090 & 0.147 \\
\hline Monitor & 0.807 & 0.184 & 0.090 & 0.147 \\
\hline Side Effects 1 & 0.248 & 0.196 & 0.226 & 0.866 \\
\hline Side Effects 2 & 0.175 & 0.150 & 0.121 & 0.877 \\
\hline Side Effects 3 & 0.209 & -0.039 & 0.679 & 0.550 \\
\hline Side Effects 4 & 0.859 & 0.034 & 0.238 & 0.174 \\
\hline Side Effects 5 & 0.918 & 0.235 & 0.151 & 0.199 \\
\hline Side Effects 6 & 0.262 & 0.249 & 0.357 & 0.519 \\
\hline \multicolumn{5}{|c|}{ Table 2. Factor Analysis of IR-BQII } \\
\hline
\end{tabular}

\begin{tabular}{|c|c|c|c|}
\hline Subscales & $\begin{array}{l}\text { Number } \\
\text { of Items }\end{array}$ & $\begin{array}{c}\text { Mean } \\
\text { (SD) }\end{array}$ & Alpha \\
\hline IR-BQII Total & 18 & $22.6(6.01)$ & 0.808 \\
\hline $\begin{array}{c}\text { Communication and } \\
\text { Psychological Side Effects }\end{array}$ & 8 & $8.60(2.90)$ & 0.721 \\
\hline Fatalism and Addiction & 3 & $3.70(1.15)$ & 0.691 \\
\hline Physiological Side Effects & 5 & $6.16(2.38)$ & 0.781 \\
\hline $\begin{array}{c}\text { Beliefs About Consciousness } \\
\text { Status }\end{array}$ & 2 & $2.16(1.15)$ & 0.77 \\
\hline \multicolumn{4}{|c|}{$\begin{array}{l}\text { Table 3. Internal Consistency and Mean Scores of The } \\
\text { Total IR-BQII and its Subscales }\end{array}$} \\
\hline
\end{tabular}




\begin{tabular}{|c|c|c|c|c|c|}
\hline Variable & Categories & Frequency & Median & \begin{tabular}{|c|} 
Interquartile \\
Range
\end{tabular} & p-Value \\
\hline \multirow{7}{*}{$\stackrel{\infty}{\infty}$} & $18-28$ & 7.1 & 18 & 7.25 & \multirow{7}{*}{$\begin{array}{l}\stackrel{*}{*} \\
\stackrel{*}{\circ} \\
\stackrel{0}{\circ} \\
0\end{array}$} \\
\hline & $29-38$ & 10.6 & 18.50 & 7 & \\
\hline & $39-48$ & 15.9 & 19.47 & 7 & \\
\hline & $49-58$ & 30.6 & 21 & 5 & \\
\hline & $59-68$ & 17.1 & 22 & 6.5 & \\
\hline & $69-78$ & 15.3 & 19 & 5 & \\
\hline & $79-88$ & 3.5 & 20.50 & 4.75 & \\
\hline \multirow{2}{*}{ 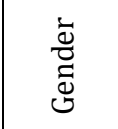 } & Male & 42.4 & 20 & 4.75 & \multirow{2}{*}{ 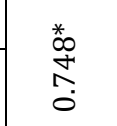 } \\
\hline & Female & 57.6 & 20 & 5.50 & \\
\hline \multirow{6}{*}{ 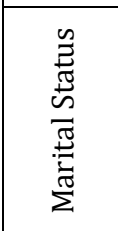 } & Separated & 28.24 & 21 & 5 & \multirow{6}{*}{$\begin{array}{l}\stackrel{*}{*} \\
\stackrel{*}{\circ} \\
\text { m } \\
0\end{array}$} \\
\hline & Widowed & 22.94 & 20 & 6 & \\
\hline & Divorced & 4.11 & 20 & 10 & \\
\hline & Single & 34.71 & 20 & 4 & \\
\hline & Married & 7.65 & 19 & 6.50 & \\
\hline & Other & 2.35 & 19 & 11 & \\
\hline \multirow{7}{*}{ 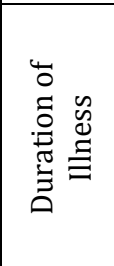 } & $<=6$ & 34.91 & 21 & 5 & \multirow{7}{*}{$\begin{array}{l}\stackrel{*}{*} \\
\stackrel{*}{\varpi} \\
\stackrel{m}{0}\end{array}$} \\
\hline & $6-12$ & 21.89 & 19 & 4.50 & \\
\hline & $12-24$ & 13.61 & 20 & 4 & \\
\hline & $24-36$ & 7.10 & 20 & 6.5 & \\
\hline & $36-48$ & 2.96 & 24 & 6.5 & \\
\hline & $48-60$ & 6.51 & 20 & 7 & \\
\hline & $>60$ & 5.92 & 19 & 13.25 & \\
\hline \multicolumn{6}{|c|}{$\begin{array}{c}\text { Table 4. Descriptive Statistics and Non-Parametric Test } \\
\text { Results to Evaluate the Relation Between the Total IR-BQII } \\
\text { Score and Demographic Variables }\end{array}$} \\
\hline \multicolumn{6}{|c|}{ *Mann-Whitney test 2-tailed p-value } \\
\hline
\end{tabular}

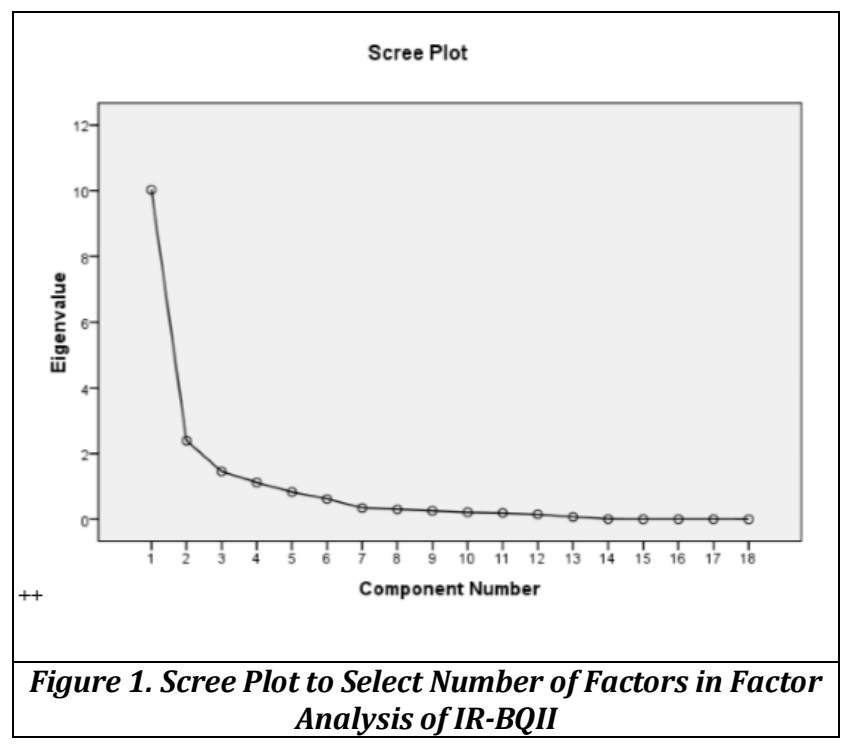

\section{DISCUSSION}

The Iranian version of BQII, presented in this study is both reliable and valid. The scale has an internal consistency with alpha value of 0.708 . Alpha coefficients of the four factors ranges between 0.691 and 0.781 . Item loadings according to FA confirms these results. Although the four factors identified in the factor analysis of the scale does not comply with the 8 proposed theoretical concepts, ${ }^{(49)}$ but it is logically structured according to theory and most items are covered with a variance of $83.33 \%$.

Community and psychological factors constitute 8 questions of 18 IR-BQII questions. Initially only three out of five communicational items of IR-BQII were loaded in first factor, but for theoretical reasons and cohesion, they were all added to this factor. Also, it is worth mentioning that a communicational item regarding the belief that "a strong patient shouldn't talk about pain", despite being loaded within four factors, was considered in factor one, to preserve the integrity and theoretical validity of items. Furthermore, fatalism was loaded within three factors with highest loading in factor one, but it was moved to factor two to create coherence. The item concerning constipation side effect, predicted by both factors, was also moved to physiologic side effect factor. This rearrangement of items between factors may be due to low value of alpha 0.691 .

Poor concurrence between the proposed factors in our study with the main scale could be because of cultural differences in expression, impression, notion and treatment of pain in different communities. In addition to cultural differences, language differences, terminology and even translation can be a reason.

Median of the IR-BQII scale was 24 with an interquartile range of 8 (Mean=22.6 \pm 6.0 ). A higher score indicates patient's misconception of pain and its treatment. In our study, we had more barriers than other studies, this is probably due to culture influences on treatment beliefs in Iran. Specially, the notion that a patient under treatment has to obey and is not involved in the process even in the treatment-planning phase was frequently mentioned. Furthermore, it may be due to improper pain assessment in Iran; as an example, the authors are aware that self-report pain scale of $0-10$ is not used in Iran and patients were not familiar with its use and meaning.

In our study, the least important obstacles were factors related to concerns about consciousness with a standard score of 6 . The main barrier to pain management in Iranian patients was communication and mental factor with standard score of 23.88. This is attributable to non-involvement of patient in the treatment process and lack of proper doctorpatient communication, as stated earlier. Drug effects and communication factors were previously revealed as the main barrier to pain management in other studies. $(49,50,53)$.

Our findings showed no significant effect of marital status, sex and duration of illness on IR-BQII score, which is inconsistent with earlier studies.(49) We observed significant correlation between age and barrier severity, so the score of perceived barriers for patients in 49-58 age-group was higher than the other patients. This result is in accordance with a study in Iceland.(49) Most patients in this age group are less educated and even illiterate, therefore lack of awareness about cancer and pain may be an effective factor. Other possible factors include low self-confidence and believing in a higher risk of mortality compared to younger patients.

Our results showed that the IR-BQII is a suitable tool to study pain management barriers and it is a valid and reliable instrument for physicians, nurses and other clinical staff to identify barriers and eliminate or modify them to help ease the pain of cancer patients. Further understanding of the pain management barrier in Iran, especially in middle-aged patients, is proposed for future studies.

\section{CONCLUSION}

Our results showed that the IR-BQII is a suitable tool to study pain management barriers and it is a valid and reliable instrument for physicians, nurses and other clinical staff to 
identify barriers and eliminate or modify them to help ease the pain of cancer patients. Further understanding of the pain management barrier in Iran, especially in middle-aged patients, is proposed for future studies.

\section{ACKNOWLEDGEMENTS}

This research project was approved by the Pain Research Center of Shahid Sadoughi University of Medical Sciences at Shahid Sadoughi Hospital of Yazd, Iran. The research was not financially supported, and the authors contributed voluntarily. We would like to thank Mamak Tahmasebi and Akram Mohebibeyk for their assistance. We appreciate participation of all cancer patients and oncology clinic nurses. We also express our gratitude to Sandra Ward for her valuable cooperation.

\section{REFERENCES}

[1] Khosravi A, Aghamohamadi S, Kazemi E, et al. Mortality profile in Iran (29 provinces) over the years 2006 to 2010. Ministry of Health and Medical Education, Tehran, Iran. 2013: p. 139-41.

[2] Akbari ME, Abachizadeh K, Tabatabaei SM, et al. Cancer in Iran. $1^{\text {st }}$ edn. Qom: Darolfekr Publications 2008. (In Persian).

[3] Joghataei MT, Nejati V. Assessment of health status of elderly people in the city of Kashan. Salmand, Iran J Ageing 2006;1(1):3-10.

[4] Ferris FD, Balfour HM, Bowen $\mathrm{K}$, et al. A model to guide patient and family care: based on nationally accepted principles and norms of practice. J Pain Symptom Manage 2002;24(2):106-23.

[5] Yates PM, Edwards HE, Nash RE, et al. Barriers to effective cancer pain management: a survey of hospitalized cancer patients in Australia. J Pain Symptom Manage 2002;23(5):393-405.

[6] Brazil K, Thomas D. The role of volunteers in a hospital-based palliative care service. J Palliat Care 1995;11(3):40-2.

[7] Dworkin SF, Von Korff M, LeResche L. Multiple pains and psychiatric disturbance. An epidemiologic investigation. Arch Gen Psychiatry 1990;47(3):239-44.

[8] Hellström Y, Hallberg IR. Perspectives of elderly people receiving home help on health, care and quality of life. Health Soc Care Community 2001;9(2):61-71.

[9] Ferrell BA. Pain management in elderly people. J Am Geriatr Soc 1991;39(1):64-73.

[10] Jacox A, Carr DB, Payne R. New clinical-practice guidelines for the management of pain in patients with cancer. N Engl J Med 1994;330(9):651-5.

[11] Parmelee PA. Assessment of pain in the elderly. In: Lawton MP, Teresi JA, eds. Annual review of gerontology and geriatrics: focus on assessment techniques. New York: Springer 1994: p. 281-301.

[12] Anderson KO, Syrjala KL, Cleeland CS. How to assess cancer pain: Handbook of pain assessment. Turk DC, Melzack R, eds. $2^{\text {nd }}$ edn. New York, NY: Guilford Press 2011: p. 579-600.

[13] Wallace M. Assessment and management of pain in the elderly. Medsurg Nurs 1994;3(4):293-8.

[14] Ferrell BA, Ferrell BR. Pain management at home. Clin Geriatr Med 1991;7(4):765-76.
[15] Zeydi MI, Khalaj M, Jahromi NMM. Quality of life assessment in elderly people that experiencing low back pain. Iran J Ageing 2007;1(2):119-24.

[16] Moghadam AMA, Karimzadeh N, Amarloo P. The role of pain-related beliefs in cancer adaptation. Daneshvar Raftar 2005;12(13):1-22.

[17] Yildirim YK, Uyar M, Fadillioğlu C. Kanser ağrısı ve yașam kalitesine etkisi [Cancer pain and its influence on quality of life]. Ağrı Derg J Turkish Soc Algol 2005; 17(4):17-22.

[18] Pargeon KL, Hailey BJ. Barriers to effective cancer pain management: a review of the literature. J Pain Symptom Manage 1999;18(5):358-68.

[19] Ferrell BR. The impact of pain on quality of life. A decade of research. Nurs Clin North Am 1995;30(4):609-24.

[20] Bostrom B, Sandh M, Lundberg D, et al. Cancer patients' experiences of care related to pain management before and after palliative care referral. Eur J Cancer Care (Engl) 2004;13(3):238-45.

[21] Bağçivan G, Tosun N, Kömürcü Ș, et al. Analysis of patient-related barriers in cancer pain management in Turkish patients. J Pain Symptom Manage 2009;38(5):727-37.

[22] Barg FK, Pasacreta JV, Nuamah IF, et al. A description of a psychoeducational intervention for family caregivers of cancer patients. J Fam Nurs 1998;4(4):394-413.

[23] Weeks LE, Macquarrie C, Bryanton O. Hospice palliative care volunteers: a Unique Care Link. J Palliat Care 2008;24(2):85-93.

[24] Mount B. Whole person care: beyond psychosocial and physical needs. Am J Hosp Palliat Care 1993;10(1):2837.

[25] Van Manen M. Human science for an action sensitive pedagogy. In: Researching lived experience. New York: State University of New York Press 1990: p. 202.

[26] Persaud R. Re: caregivers and existential and spiritual distress. J Pain Symptom Manage 2006;32(6):516-7,8.

[27] Bruce A, Boston P. The changing landscape of palliative care. J Hosp Palliat Nurs 2008;10(1):49-55.

[28] Donadio G. Improving healthcare delivery with the transformational whole person care model. Holist Nurs Pract 2005;19(2):74-7.

[29] Elder JP, Ayala GX, Harris S. Theories and intervention approaches to health-behavior change in primary care. Am J Prev Med 1999;17(4):275-84.

[30] Bandura A, O'Leary A, Taylor CB, et al. Perceived selfefficacy and pain control: opioid and nonopioid mechanisms. J Pers Soc Psychol 1987;53(3):563-71.

[31] Fox J. "Notice how you feel": an alternative to detached concern among hospice volunteers. Qual Health Res 2006;16(7):944-61.

[32] Charmaz K. Loss of self: a fundamental form of suffering in the chronically ill. Sociol Heal Illn 1983;5(2):168-95.

[33] Tan G, Jensen MP, Robinson-Whelen S, et al. Measuring control appraisals in chronic pain. J Pain 2002;3(5):385-93.

[34] Edwards HE, Nash RE, Yates PM, et al. Improving pain management by nurses: a pilot peer intervention program. Nurs Health Sci 2001;3(1):35-45. 
[35] Riddell A, Fitch MI. Patients' knowledge of and attitudes toward the management of cancer pain. Oncol Nurs Forum 1997;24(10):1775-84.

[36] Clarke EB, French B, Bilodeau ML, et al. Pain management knowledge, attitudes and clinical practice: the impact of nurses' characteristics and education. J Pain Symptom Manage 1996;11(1):18-31.

[37] O'Brien S, Dalton JA, Konsler G, et al. The knowledge and attitudes of experience oncology nurses regarding the management of cancer-related pain. Oncol Nurs Forum 1996;23(3):515-21.

[38] Fife BL, Irick N, Painter JD. A comparative study of the attitudes of physicians and nurses toward the management of cancer pain. J Pain Symptom Manage 1993;8(3):132-9.

[39] Cleeland CS, Chapman CR. Documenting barriers to cancer pain management. In: Foley KM, edr. Current and emerging issues in cancer pain: research and practice. New York: Raven Press Ltd., 1993: p. 321-30.

[40] Ward SE, Goldberg N, Miller-McCauley V, et al. Patientrelated barriers to management of cancer pain. Pain 1993;52(3):319-24.

[41] Lundorff L, Peuckmann V, Sjogren P. Pain management of opioid-treated cancer patients in hospital settings in Denmark. Acta Anaesthesiol Scand 2008;52(1):13742.

[42] Ozkan A. A pain assessment in cancer patients. In: Proceedings of the XIII Turkish Pediatric Oncology Group, National Pediatric Cancer Congress, Cappadocia, Turkey, 2004.

[43] Paice JA, Toy C, Shott S. Barriers to cancer pain relief: fear of tolerance and addiction. J Pain Symptom Manage 1998;16(1):1-9.
[44] Cleeland CS, Gonin R, Hatfield AK, et al. Pain and its treatment in outpatients with metastatic cancer. N Engl J Med 1994;330(9):592-6.

[45] Foley KM. The treatment of cancer pain. N Engl J Med 1985;313(2):84-95.

[46] Aydinli I. Kanser Ağrısı [Cancer Pain]. Klin Gelisim Dergisi: Journal Clin Dev 2004;17(1):3-15.

[47] Mercadante S. Predictive factors and opioid responsiveness in cancer pain. Eur J Cancer 1998;34(5):627-31.

[48] Du Pen SL, Du Pen AR, Polissar N, et al. Implementing guidelines for cancer pain management: results of a randomized controlled clinical trial. J Clin Oncol 1999;17(1):361.

[49] Gunnarsdottir S, Serlin RC, Ward S. Patient-related barriers to pain management: the Icelandic Barriers Questionnaire II. J Pain Symptom Manage 2005;29(3):273-85.

[50] Lin CC. Barriers to the analgesic management of cancer pain: a comparison of attitudes of Taiwanese patients and their family caregivers. Pain 2000;88(1):7-14.

[51] Wells N, Johnson RL, Wujcik D. Development of a short version of the Barriers Questionnaire. J Pain Symptom Manage 1998;15(5):294-8.

[52] Robinson K, Monsivais D. Reliability and validity of 2012 Spanish translation of Barriers Questionnaire II (BQ-II). J Pain 2013;14(4):S97.

[53] Vallerand AH, Collins-Bohler D, Templin T, et al. Knowledge of and barriers to pain management in caregivers of cancer patients receiving homecare. Cancer Nurs 2007;30(1):31-7. 